\title{
Appropriate Nutrition for Preventing Osteoporosis
}

Yaeko Ominato $^{1}$, Masaki Kaneko ${ }^{2}$, Mori Tomohisa ${ }^{1,5}$, Susumu Ito ${ }^{3}$ and Katsuhiko Hata ${ }^{1,3,4, *}$

${ }^{1}$ Department of Neuroscience, Research Center for Mathematical Medicine, Kokushikan University, Japan

${ }^{2} \mathrm{KYB}$ medical service co., Ltd., Japan

${ }^{3}$ Department of Sport and Medical Science, Kokushikan University, Japan

${ }^{4}$ MYCELL Clinic Tokyo, Japan

${ }^{5}$ NAGOMI Clinic, Japan

\section{Abstract}

In general, osteoporosis is treated in orthopaedics by standard medical procedures including drug therapy, exercise therapy and diet therapy. We have tried to apply molecular nutrition in our hospital conducting blood and urine tests on more than 60 items to elucidate the mechanism of osteoporosis and to search for better treatment of osteoporosis. In this paper, we report the prospect of a molecular nutritional approach to the study of mechanism and better treatment of osteoporosis based on our experiences in our hospital.

\section{Publication History:}

Received: December 10, 2019

Accepted: December 28, 2019

Published: December 30, 2019

\section{Keywords:}

Molecular nutrition Motor Osteoporosis, Drug therapy, Exercise therapy, Diet therapy.

\section{Abbreviations}

IL-1: interleukin 1; TNF: tumour necrosis factor; GM-CSF: granulocyte macrophage colony-stimulating factor; ucOC: under carboxylated osteocalcin; OC: osteocalcin; TRACP 5b: tartrate resistant acid phosphatase isoform 5b; PTH: parathyroid hormone, VD3: vitamin D3, CT: calcitonin, VDRE: vitamin D response element

\section{Introduction}

In general, osteoporosis is treated in orthopaedics by standard medical procedures including drug therapy, exercise therapy and diet therapy. We have tried to apply molecular nutrition in our hospital conducting blood and urine tests on more than 60 items to elucidate the mechanism of osteoporosis and to search for better treatment of osteoporosis. In this paper, we report the prospect of a molecular nutritional approach to the study of mechanism and better treatment of osteoporosis based on our experiences in our hospital.

\section{Mechanism of bone Metabolism}

In bone, bone resorption by osteoclasts and bone formation by osteoblasts are repeatedly performed (bone metabolism), and progenitor cells are activated to proliferation and differentiation. During this process, they are known to receive control of various hormones and many cytokines. Osteoporosis is considered to be caused by the imbalance of this control mechanism of bone metabolism.

Postmenopausal osteoporosis is caused by decreased estrogen secretion associated with increased cytokine levels such as IL-1, TNF, and GM-CSF, decreased $1.25(\mathrm{OH} 2)$ D3 production, decreased parathyroid hormone (PTH) and calcitonin (CT) secretion resulting in increases bone resorption [1]. Thereafter, bone formation is reactively enhanced, but the bone density continues to decrease because the degree of enhanced bone resorption is greater than that of secondary enhanced bone formation $[2,3]$. Thus, postmenopausal osteoporosis is mainly high-turnover types. On the other hand, senile osteoporosis is, though it still has many unclear points, mainly lowturnover type caused by a relative deficiency of bone formation due to ageing-related various functional declines.

In our hospital, osteocalcin (OC) and undercarboxylated osteocalcin (ucOC) are used as bone metabolism markers, and tartrate-resistant acid phosphatase isoform $5 \mathrm{~b}$ (TRACP $5 \mathrm{~b}$ ) is used to assess bone status and therapeutic effects. Treatments are carried out by molecular nutritional techniques, monitoring bone metabolism markers, to improve bone metabolism, so that bone formation exceeds bone resorption.

\section{Molecular Nutritional Technique}

Calcium, the most important nutrient for increasing bone mass, is $99 \%$ distributed in bone, $1 \%$ in soft tissue, and $0.1 \%$ in blood. Calcium works not only for bone formation but also for the trigger of secretion of hormones and neurotransmitters, of muscle contraction and of blood clotting. Therefore, dietary intake of calcium is very important and the recommended daily dose is about $650 \mathrm{mg}$ to $800 \mathrm{mg}$ for adults, although there are differences depending on age and gender. However, the Japanese average intake of calcium, both adult man and female, remains about $500 \mathrm{mg} /$ day (survey by the Ministry of Health, Labor and Welfare in 2015). Deficiency of calcium intake stimulates secretion of parathyroid hormone which causes calcification of the arteries by calcium leached from the bone, causing atherosclerosis, hypertension and heart diseases [4,5]. On the other hand, the curious phenomenon called "Calcium Paradox" has been reported: in the countries with higher calcium intake per person per day has a higher number of bone diseases including osteoporosis [6,7]. The term "Calcium Paradox" originally indicates an increase of cellular calcium influx efficacy by lowered extracellular calcium concentration, but now it is widely used to indicate paradoxical response to calcium intake. The mechanism of that phenomenon is considered as follows:

*Corresponding Author: Prof. Katsuhiko Hata, Department of Neuroscience, Research Center for Mathematical Medicine, Kokushikan University, Japan; E-mail: khata@kokushikan.ac.jp

Citation: Ominato Y, Kaneko M, Tomohisa M, Ito S, Hata K (2019) Appropriate Nutrition for Preventing Osteoporosis. Int J Phys Ther Rehab 5: 159. doi: https:// doi.org/10.15344/2455-7498/2019/159

Copyright: (c) 2019 Ominato et al. This is an open-access article distributed under the terms of the Creative Commons Attribution License, which permits unrestricted use, distribution, and reproduction in any medium, provided the original author and source are credited. 
Higher calcium intake correlates with higher animal protein intake. Calcium is mobilized from bone for neutralizing sulphur-containing acidic amino acid residues, such as methionine and cysteine, causing bone mass density reduction [8]. Thus, not only calcium intake but also avoiding excessive intake of animal proteins, which are high in sulfur-containing amino acids, especially cystine and methionine, to prevent loss of bone calcium may be important for the prevention of osteoporosis.

Since serum calcium concentration is strictly controlled by the homeostatic mechanism of calcium control hormones (PTH, VD3, CT), it is difficult to judge whether calcium metabolism is functioning normally by serum calcium concentration alone. It is necessary to survey the dynamics of calcium in the body also from blood PTH and VD3 concentration, urinary calcium concentration and $\mathrm{pH}$, bone density, and meal content.

Thus, calcium is a very important mineral for the prevention and treatment of osteoporosis. However, it is not sufficient to take calcium alone. Many previous studies have shown no significant correlation between dietary calcium intake and bone loss [3,9-13]. While about $80 \%$ of the bone components are calcium phosphate, remaining about $20 \%$ is bone matrix and cells containing collagen and other proteins. Therefore, nutritional therapy for osteoporosis is performed by supplementing, in addition to calcium, various nutrients described below.

\section{Vitamin D and vitamin A}

Vitamin D activates bone metabolism such as synthesis of bone matrix (collagen, osteocalcin) and differentiation of osteoclasts. It also promotes the synthesis of calbindin. Calbindin, known as a calciumbinding protein in the small intestine, has in its gene a vitamin $\mathrm{D}$ response element (VDRE), so that its synthesis is promoted by vitamin D. Vitamin D has been also reported to activate immune system of infection defence via Toll-like receptor, as well as other differentiation induction actions [15-19]. Vitamin D and Vitamin A interact in the nucleus through the cross-talking of Vitamin D receptor (VDR) and retinoid X receptor (RXR). Thus, supplementation of Vitamin D and $\mathrm{A}$ is important for the activation of bone metabolism.

\section{Protein, vitamin $\mathrm{C}$, vitamin $\mathrm{K}$, and Iron}

Protein is necessary for the activation of bone metabolism and synthesis of the bone matrix which is mainly composed of collagen fibres. Bone matrix calcification is initiated by matrix vesicles produced and secreted by osteoblasts. The matrix vesicles contain calcified spheres composed of calcium phosphate crystals which contact collagen fibres secreted from osteoblasts and orderly calcification proceeds on the collagen fibre [20]. Vitamin C and iron are required for collagen synthesis, and chronic iron deficiency has been pointed out to increase the risk of osteoporosis [21].

Osteocalcin (OC) is a major non-collagen protein in the bone matrix, and plays an important role in calcium binding and stabilization of hydroxyapatite, regulating bone formation locally [22]. OC is incorporated into the bone matrix after $\gamma$-carboxylation of glutamate residues by $\gamma$-carboxylase. At this time, vitamin $\mathrm{K}$ acts as a coenzyme of $\gamma$-carboxylase. Insufficient vitamin $\mathrm{K}$ produces OC that does not function normally, called undercarboxylated osteocalcin (ucOC). Therefore, an increase in blood ucOC suggests a lack of vitamin $\mathrm{K}$ and a decrease in normal functioning OC. Vitamin $\mathrm{K}$ is mainly synthesized by intestinal bacteria and vitamin $\mathrm{K}$ deficiency is suggested to be caused not only by vitamin $\mathrm{K}$ antagonist such as warfarin but also vitamin $\mathrm{K}$ malabsorption in the ileum associated with chronic gastrointestinal disorders [23]. In our hospital, we also observed that most of the patients with high ucOC were associated with malabsorption syndrome of some cause. Thus, for treatment of osteoporosis, normalizing the intestinal environment is important as well as supplementing nutrients such as high-quality proteins, vitamin $\mathrm{C}$, iron and vitamin $\mathrm{K}$.

\section{Magnesium (Mg)}

Mg deficiency is considered as one of the risk factors of osteoporosis because it affects the secretion and activity of PTH and vitamin D $[24,25]$. An epidemiological survey has also shown a significant positive correlation between daily $\mathrm{Mg}$ intake and bone mineral density. Thus, eating a well-balanced diet of magnesium and calcium is important for bone mineral stabilization.

\section{Isoflavone}

Isoflavone which binds to the estrogen receptor as an agonist has an estrogenic effect. It is expected to be effective in preventing the onset of postmenopausal osteoporosis, caused by estrogen deficiency, as has already been confirmed in animal studies and epidemiological studies [26].

\section{Conclusion}

In addition to supplying various nutrients mentioned above, it is important for the prevention and treatment of the osteoporosis to improve insulin resistance, reduce oxidative stress, and optimize the immune system. It has long been pointed out that many diabetics have fractures. Recent studies have suggested that advanced glycation end products (AGEs) and oxidative stress are involved in the development of osteoporosis and vascular calcification [27]. The immune system is also related to bone metabolism as the osteoclasts originate from macrophages. Moreover, inflammation is associated with insulin resistance $[28,29]$. Thus, insulin resistance, oxidative stress, and the immune system interact mutually to cause osteoporosis pathogenesis. By the further elucidation of these mechanisms, it is expected to lead to a more sophisticated approach for osteoporosis treatment.

\section{Competing Interests}

The authors declare that they have no competing interests.

\section{References}

1. Wakatsuki A (2006) Case Study and Primary Care Medicine: Osteoporosis, Acta obstetrica et Gynaecologica Japonica 58: 27-31.

2. Pfeilschifter J, Bonewald L, Mundy GR (1990) Characterization of the latent transforming growth factor beta complex in bone. J Bone Miner Res 5: 4958.

3. Riggs BL (1987) Pathogenesis of osteoporosis. Am J Obstet Gynecol 156: $1342-1346$

4. Hulsmann WC (2000) Morphological changes of heart muscle caused by successive perfusion with calcium-free and calcium-containing solutions (calcium paradox). Cardiovasc Res 45: 119-120.

5. Persy V, D'Haese P (2009) Vascular calcification and bone disease: the calcification paradox. Trends in molecular medicine 15: 405-416. 
6. Breslau NA, Brinkley L, Hill KD, Pak CY (1988) Relationship of animal protein-rich diet to kidney stone formation and calcium metabolism. J Clin Endocrinol Metab 66: 140-146.

7. Hegsted DM (1986) Calcium and osteoporosis. J Nutr 116: 2316-2319.

8. Protein and amino acid requirements in human nutrition (2007) World Health Organization technical report series.

9. Hosking DJ, Ross PD, Thompson DE, Wasnich RD, McClung $M$, et al (1998) Evidence that increased calcium intake does not prevent early postmenopausal bone loss. Clinical therapeutics 20: 933-944.

10. Riggs BL, Wahner HW, Melton LJ 3rd, Richelson LS, Judd HL, et al. (1987) Dietary calcium intake and rates of bone loss in women. J Clin Invest 80 : 979-982.

11. van Beresteijn EC, van 't Hof MA, Schaafsma $G$, de Waard $H$, Duursma SA, et al. (1990) Habitual dietary calcium intake and cortical bone loss in perimenopausal women: a longitudinal study. Calcified tissue international 47: $338-344$

12. Nakamura K, Oyama M, Saito T, Oshiki R, Kobayashi R, et al. (2012) Nutritional and biochemical parameters associated with 6-year change in bone mineral density in community-dwelling Japanese women aged 69 years and older: The Muramatsu Study. Nutrition 28: 357-361.

13. Reid IR, Bristow SM, Bolland MJ (2015) Calcium supplements: benefits and risks. Journal of internal medicine 278: 354-368.

14. Carlberg C, Bendik I, Wyss A, Meier E, Sturzenbecker LJ, et al. (1993) Two nuclear signalling pathways for vitamin D. Nature 361: 657-660.

15. Abe E, Miyaura C, Sakagami H, Takeda M, Konno K, et al. (1981) Differentiation of mouse myeloid leukemia cells induced by 1 alpha, 25-dihydroxyvitamin D3. Proc Natl Acad Sci U S A 78: 4990-4994.

16. Deluca HF, Cantorna MT (2001) Vitamin D: its role and uses in immunology FASEB J 15: 2579-2585.

17. Liu $M$, Lee $M H$, Cohen $M$, Bommakanti $M$, Freedman LP, et al. (1996) Transcriptional activation of the Cdk inhibitor p21 by vitamin D3 leads to the induced differentiation of the myelomonocytic cell line U937. Genes Dev 10: 142-153.

18. Michigami T, Ozono $\mathrm{K}$ (2006) Progress in research on vitamin D. Tanpakushitsu kakusan koso 51: 1836-1846.

19. Liu PT, Stenger S, Li H, Wenzel L, Tan BH, et al. (2006) Toll-like receptor triggering of a vitamin D-mediated human antimicrobial response. Science 311: 1770-1773.

20. Amizuka N, Hongo H (2015) Histological and Ultrastructural Findings on Bone Cells. Microscopy 50: 191-196.

21. Toxqui L, Vaquero MP (2015) Chronic iron deficiency as an emerging risk factor for osteoporosis: a hypothesis. Nutrients 7: 2324-2344.

22. Hadjidakis DJ, Androulakis II (2006) Bone remodeling. Ann N Y Acad Sci 1092: 385-396

23. Krasinski SD, Russell RM, Furie BC, Kruger SF, Jacques PF, et al. (1985) The prevalence of vitamin $\mathrm{K}$ deficiency in chronic gastrointestinal disorders. Am J Clin Nutr 41: 639-643.

24. Castiglioni S, Cazzaniga A, Albisetti W, Maier JA (2013) Magnesium and osteoporosis: current state of knowledge and future research directions. Nutrients 5: 3022-3033.

25. Sahota O, Mundey MK, San P, Godber IM, Hosking DJ, et al. (2006) Vitamin $D$ insufficiency and the blunted PTH response in established osteoporosis: the role of magnesium deficiency. Osteoporos Int 17: 1013-1021.

26. Ma DF, Qin LQ, Wang PY, Katoh R (2008) Soy isoflavone intake increases bone mineral density in the spine of menopausal women: meta-analysis of randomized controlled trials. Clin Nutr 27: 57-64.

27. Yamagishi S (2011) Role of advanced glycation end products (AGEs) in osteoporosis in diabetes. Current drug targets 12: 2096-2102.

28. Umeda S, Takahashi K, Naito M, Shultz LD, Takagi K, et al. (1996) Neonatal changes of osteoclasts in osteopetrosis (op/op) mice defective in production of functional macrophage colony-stimulating factor (M-CSF) protein and effects of M-CSF on osteoclast development and differentiation. Submicrosc Cytol Path 28: 13-26.

29. de Luca C, Olefsky JM (2008) Inflammation and Insulin Resistance. FEBS letters 582: 97-105. 